\title{
Reflecting on the design and development of the interview process in a doctoral research project using john's model of reflection.
}

\author{
Mr. Allan Seraj RN
}

\begin{abstract}
The design and development of the interview process, in a doctoral research project, is significantly enhanced by the use of a structured model of reflection to enable reflecting on feedback obtained from peers, research participants and the use of a reflexive journal. The act of reflection, in the research process, augments the researcher's confidence, his research journey and also engages the researcher in a cycle of personal and professional change.
\end{abstract}

Keywords: Feedback, Reflection, Semi-structured interview

\section{Introduction}

This paper is a reflective essay that explores the evolution and journey of a doctoral student in the development of the interview process that will be used for data collection in his research project. The reflection is based on the feedback received from pilot interviews, peer review and the use of a reflexive journal. In order to structure the reflective process, Johns model of reflection (1995) will be utilized. The paper is centered on an agreed outcome within the learning contract between the student and his academic supervisor. The use of "I" will be used to maintain reflexivity as discussed by Hamill (1999).

There are many definitions for reflection: " a thought, idea, or opinion formed, or a remark made, as a result of meditation" (Webster Dictionary1995), or "a cognitive process in which the person attempts to increase his or her awareness of personal experiences and therefore his or her ability to learn from them" as suggested by Gordon \& Smith Hullfish (1961). In learning theory, according to Smith and Irby (1997) and Kolb (1994), reflection is defined as "a composite of skills, knowledge, attitudes, and values alongside the learners' cognitive framework So, the conscious act of reflection allows for the assimilation and reordering or reworking of into pre-existing knowledge processes". This contributes to the development of the learner's confidence, and has been shown by Sprinthall (1994), that psychological growth occurs only when reflection is a component of an educational program. Thus, reflection leads to the growth of the individual: morally, personally, psychologically, and emotionally, as well as cognitively.

John's model of reflection (1995) is used in this essay because the cues are simple; the cues help me with my focus and afford me a high degree of structure for reflection. The use of a structured model of reflection, as substantiated by Atkins and Murphy (1994 p 49-56) "helps to focus the reflective process, and involves looking back on experience(s) so as to learn from them and gain new or deeper understanding about practice development and develop alternative ways of acting when leading and facilitating the development of practice. It is also about connecting personal learning and ways of knowing with other types of learning and knowledge".

\section{Description of the experience}

As a doctoral student engaging in the research process, my main method of data collection is semi-structured interviews. The plan was to obtain signed consent from the participants and invite them to take part in an individual face-to-face semi structured 
On receiving ethical approval from the university, I conducted six (6) pilot interviews to 'test' the semi-structured questionnaire proforma. During each interview, with the participant's agreement, I took random notes to consolidate my thoughts and returned to them for clarification of ideas after the interviews. After each pilot interview, I asked the participant to provide feedback about the interview with the emphasis being on my interviewing skills. Coupled with this, I kept a reflexive journal where I reflected on each interview. I also searched the literature to augment my interviewing technique. In order to strengthen my interview schedule, I invited my colleague, and head of my Trust's research department, to peer review my interview proforma and provide written feedback.

\section{Refection}

As I wrote my research proposal, I was attempting to map out how I was going to stage each part of my research. The choice of data collection tool is important to ensure that the right data is collected to answer the opportunities to immerse myself into the interview discussion, failed to pick up cues from the participants, and in one case, lost the engagement of the participant because they did not fully understand what I was trying to ask. There were also times during the interview where the jargon I used may have been too complex. Written comments from my peer review demonstrated that my interview schedule and overall approach to interviewing needed improving. I also wrote about my interviewing experience in my journal after each interview. The feedback and self-reflection illuminated my understanding and helped me to prepare for the next interview.

\section{Influencing factors}

In my limited experience as a researcher, I have always stayed close to research methods that were simple and structured. The challenge of participating in a process that had 'open ends' was daunting. My own knowledge base has always been focused on quantitative research and launching into qualitative methods was research question and fit the methodology: the research method must match the methodology.

The use of the semi-structured questionnaire, as a data collection tool, afforded me a great deal of flexibility and allowed me to My peer substantiated the fact that experience, in using the interviewing technique, will make it easier to engage with the research method and, subsequently, data collection would become more meaningful. This reassured me as a researcher and I began to understand how the evolution of my interviewing technique could enhance my overall research project and the development of my personal skills of listening, empathy and non-verbal communication.

uncomfortable. I have always relied on quantitative data in my decision making and subsequently, I had to restructure the way I approach the ideology of qualitative research both for the research probe into issues and concepts in a deeper way that other methods may not have offered. In the initial stages of using the tool, I began to realize that flexibility and depth must be aligned to experience when using this method. In some instances, I missed project and in my own practice.

On reflection, I believe that I could have had the peer review of the interview tool before the pilot interviews. This may have contributed to the development of the tool, enhance my approach with the participants 
and strengthen the interview process. I could have also met with my supervisor after each interview to reflect on the interviewing technique and any areas for development. These approaches may have augmented the evolution of the interview tool and thereafter, each subsequent interview would have been of a 'better' quality in relation to data richness and my own development as an interviewer.

In thinking about the other choices I had in relation to the research method, I could have done a structured open-ended questionnaire but it is questionable whether I would have obtained the richness of data that has been generated from my preferred method in the pilot interviews. Also, the chosen methodology is apt for a semi-structured approach, as it requires the participants to talk openly about their experiences, and allows the interviewer to probe deeper into emerging ideas and issues from the dialogue.

\section{Learning}

As I reflect on the feedback given to me by my peer, the feedback given to me by the participants and my journal entries, I have changed my approach to interviewing using the semi-structured method. My understanding of the interview process has evolved and my skills as an interviewer have improved. I am now able to conduct the interview with a better understanding and respect for the interview process. This has contributed to my confidence as an interviewer and researcher. Epistemologically, the evolution of developing my interview process has enhanced me empirically, ethically, personally and aesthetically. These are now discussed.

Empirically, my research project uses Grounded Theory (GT), a research methodology developed originally by Glaser and Strauss (1967) and described by Strauss and Corbin (1990) as the most applicable for the study as it relates to the philosophical base of the study. This methodology allows the researcher to immerse himself in the data and question the makeup of the theoretical category in relation to the data instances composition. The methodology is a general qualitative research methodology used for developing theory that is grounded in the data, which is systematically gathered and analysed. The theory develops and evolves during the research process due to the interplay between the data collection and analysis phases. One important feature of GT is theoretical sensitivity: the process of developing conceptual insight that is used by the researcher as he comes into the research situation (Glaser, 1978). A grounded theory study results in the generation of a theory, consisting of a set of plausible relationships proposed among concepts and sets of concepts (Glaser, 1978).

The social constructivist framework is used in the study as it acknowledges the complexity and uniqueness of the learner and encourages the learner to be an integral part of the learning process (Wertsch 1997). Further to this, the study's perspective is interpretative and the four philosophical assumptions support this standpoint: (i) ontologically, the study is socially constructed with multiple realities (ii) epistemologically: the study is subjective because knowledge is derived from the researcher-participant interaction, (iii) methodologically: the study is hermeneutically based as the analysis of the data will be based on text interpretation and (iv) axiologically: understanding and truth is situated in the context of the study and is descriptive.

As discussed above, methodologically, the study is hermeneutically based and text interpretation will be used in the analysis and knowledge is derived from the interaction between the researcher and participant. In order to facilitate the philosophical assumptions of the research project, semi- 
structured interviewing is used. Semistructured interviewing is more flexible than standardised methods such as the structured interview or survey. Although I will have some established general topics for investigation, this method will allow me to explore emergent themes and ideas rather than rely only on concepts and questions defined in advance of the interview. Usually, I would use a standardized interview schedule with set questions, which will be asked of all respondents. The questions tend to be asked in a similar order and format to make a form of comparison between answers possible. However, there is also scope for pursuing and probing for novel, relevant information, through additional questions often noted as prompts on the schedule. There are times when I would have to frequently formulate impromptu questions in order to follow up leads that emerge during the interview. Usually my role is to engage and encourage but not get personally involved. I will facilitate the interviewees to talk about their views and experiences in depth but with limited reciprocal engagement or disclosure. The interview will be undertaken at a mutually agreeable time and in a setting that is convenient and appropriate to the participant. Participants will be given the right to withdraw at any time without prejudice and without providing a reason. This therefore brings me to the ethics of my learning.

My ethics or moral knowledge was guided by

(i) researcher/participant relationship, (ii) confidentiality and (iii) anonymity and informed consent. Participants had the opportunity to meet with the researcher and have any questions answered about the research before, during and after the research study. As qualitative research is emergent in design, the concept of true informed consent is problematic. Participants were given a participant information sheet and encouraged to ask further questions. According to Holloway and Wheeler (1996), informed consent should be based on the understanding that any participation in the study is voluntary. In acknowledgement of this, consent was sought prior to, during and again on completion of the interview; consent was on going throughout the process in recognition of the changing dynamics of qualitative research.

Qualitative research inherently uses small cohorts, so maintaining confidentiality can be problematic. In this pilot study, all identifying characteristics, such as ethnic background, age, place of work, sex of participants and training background was part of the data collection. These pieces of data can potentially reveal the participant's identity because of the small cohort. Specific quotations and examples when disseminating research results could lead to the respondents being identified via deductive disclosure. If so, details in the data were modified. Interviews were transcribed immediately afterwards and the script given a unique number that did not identify the participant. This was explained in the individual face to face meeting, on the information sheet and consent form (Ritchie ad Lewis, 2010). At the start of the interview, it was discussed with the participant that should these issues come to light the participant will be informed that this information will need to be disclosed.

Local health \& safety 'rules' were observed and information around counseling facilities was available as required: it is recognised that there is a potential for psychological harm. This was discussed with the participant, and, should the interviewee become distressed at any time, the interview would be stopped and the researcher will step out of role to support the participant to deal with distressing issues. It is recognised that there is propensity for the following issues to be volunteered during the interview: potential feelings of inadequacy, 
bullying issues, past 'bad' mentoring/mentee experience and issues related to whistle blowing related to disclosure of poor clinical practice or clinical negligence. As part of the consent process, the participant was told that confidentiality would not be maintained in the event of disclosure of clinical negligence. The overarching principles of beneficence (to do good) and nonmalficence (to do no harm) formed the basis of my ethical knowledge in conducting the interviews in the pilot phase. I then began reflecting on my self-awareness.

Personally, accepting to engage with qualitative research was the first challenge as a researcher I had to overcome. Learning about the methodology, as discussed in the empirics, was enlightening. I began to immerse myself in the literature that defines the methodology and, slowly, my own knowledge base began to expand. At this time, I would not consider myself an expert in GT, but my expertise in the methodology has improved and I am able to understand how its application to the research process. The collaboration with my peers have strengthened my interviewing technique and enabled me to develop my knowledge and skills in the process. As I conducted each pilot interview, reflecting on each one and keeping a journal, augmented the design of the tool and further, it helped with my personal evolution of the way I conduct a semi-structured interview.

Aesthetically, as I reflect on the process of interviewing in my research project, I begin to realize that I must consider my own ways of thinking and how I learn from my practice. In attempting to understand how I was changing, I realized that I was intrinsically following Lewin's model (1951) of change: unfreezing, change and freezing. I began by 'unfreezing' my thoughts and attitudes about qualitative research and the methodology: GT. This new way of thinking initially posed a challenge to the way I conceptualised research as a tool for change in my own practice, but by engaging with the research process, I began to 'warm' to this qualitative methodology. In applying the second aspect of Lewin's model: 'change', I started applying the methodological principles of GT that I was learning, to the research process and my professional life: this augmented my research and professional confidence. In applying Lewin's third phase: 'freezing', on one level, I immersed myself into the methodological concepts and applied them to my practice as a researcher on my day-to-day journey, but, on another level, I realized that I may not be able to fully 'freeze' this change as I am constantly immersing myself in new knowledge and therefore I am caught in a loop between the first two phases of Lewin's model of constant learning and reinvesting the knowledge back into the research process.

\section{Conclusion}

Reflection, in the research process, seeks to build the confidence of the researcher both on a personal and professional level. Using a structured model of reflection has enhanced this process. In this essay, the reflection on feedback received on the research method: semi-structured questionnaires, has augmented (i) the design and development of the research tool and (ii) the researcher's ability to generate high quality data by improving his skills as an interviewer. Engaging and immersing in feedback about the research method, developed my approach as a researcher using this method in my doctoral project, and provided an opportunity to continuously learn from the journey. As I have reflected on my research journey thus far, I have realized that collaboration with peers, participants and experts in the methodology, coupled with the use of a reflexive journal significantly enhances the development of the research method. 


\section{References}

Atkins S. and Murphy K. (1994) Reflective practice. Nursing Standard. Vol. 8. No. 39. pp. 49-56.

Glaser B. (1978). Theoretical Sensitivity, Mill Valley, CA: Sociology Press.

Gordon H, Smith Hullfish, P. H. (1961) Reflective thinking: The method of education. New York: Dodd, Mead \& Co.

Hamill C. (1999) Academic essay writing in the first person: a guide for undergraduate. Nursing Standard. July 21-27; 13 (44): 3840

Holloway I, Wheeler S. (1996) Qualitative Research for Nurses. Oxford. Blackwell Science.

Johns C. (1995) Framing learning through reflection within Carper's fundamental ways of knowing in nursing. Journal of Advanced Nursing. 22, 2, 226-234

Kolb DA. (1994) Experiential Learning. Englewood Cliffs, NJ: Prentice Hall.

Lewin K. (1951) Force Theory in Social Science. New York, NY: Harper and Row.

Merriam Webster. (1995) Merriam Webster
Collegiate Dictionary. 10th ed.

Springfield, MA: 982.

Ritchie, J. and Lewis, J. (2010) Qualtative Reseaarch Practice. In: A guide for Social Science Students and Researchers. London: Sage Publication, pp.66-69, 7374.

Smith CS, Irby DM. (1997). The roles of experience and reflection in ambulatory care education. Academic Medicine. ; 72:32-5. 7.

Sprinthall NA. (1994) Counseling and social role taking: promoting moral and ego development. In: Rest JR (ed). Moral Development in the Professions: Psychology and Applied Ethics. Hillsdale, NJ: Lawrence Erlbaum Associates. 55100.

Strauss, A., \& Corbin, J. (1990). Basics of qualitative research: Grounded theory procedures and techniques. Newbury Park, CA: Sage Publications, Inc.

Wertsch JV. (1997) Mind as Action. Oxford University Press 